\title{
Pain Management In Pediatric Patients With Postural Orthostatic Tachycardia Syndrome: Current Insights
}

This article was published in the following Dove Press journal:

Journal of Pain Research

\author{
Ashley N \\ Junghans-Rutelonis (D) \\ Andrea Postier ${ }^{1,2}$ \\ Andrew Warmuth ${ }^{1,3}$ \\ Scott Schwantes' \\ Karen E Weiss ${ }^{4}$ \\ 'Department of Pain Medicine, Palliative \\ Care, and Integrative Medicine, \\ Children's Hospitals and Clinics of \\ Minnesota, Minneapolis, MN, USA; \\ ${ }^{2}$ Children's Minnesota Research Institute, \\ Children's Hospitals and Clinics of \\ Minnesota, Minneapolis, MN, USA; \\ ${ }^{3}$ Department of Physical Medicine and \\ Rehabilitation, Children's Hospitals and \\ Clinics of Minnesota, Minneapolis, MN, \\ USA; ${ }^{4}$ Department of Anesthesiology and \\ Pain Medicine, University of Washington \\ School of Medicine \& Seattle Children's \\ Hospital, Seattle, DC, USA
}

\begin{abstract}
Pediatric patients with postural orthostatic tachycardia syndrome (POTS) often present with co-occurring struggles with chronic pain (POTS+pain) that may limit daily activities. POTS is a clinical syndrome characterized by orthostatic symptoms and excessive postural tachycardia without orthostatic hypotension. Active research from the medical and scientific community has led to controversy over POTS diagnosis and treatment, yet patients continue to present with symptoms associated with POTS+pain, making treatment recommendations critical. This topical review examines the literature on diagnosing and treating pediatric POTS+pain and the challenges clinicians face. Most importantly, clinicians must employ an interdisciplinary team approach to determine the ideal combination of pharmacologic (e.g., fludrocortisone), non-pharmacologic (e.g., physical therapy, integrative medicine), and psychological (e.g., cognitive behavioral therapy, psychoeducation) treatment approaches that acknowledge the complexity of the child's condition, while simultaneously tailoring these approaches to the child's personal needs. We provide recommendations for treatment for youth with POTS+pain based on the current literature.
\end{abstract}

Keywords: youth, pediatric, postural orthostatic tachycardia syndrome, chronic pain, treatment

\section{Introduction}

Postural orthostatic tachycardia syndrome (POTS) is a clinical syndrome characterized by orthostatic symptoms and excessive postural tachycardia without orthostatic hypotension. ${ }^{1}$ It is estimated that 1 to 3 million Americans have a POTS diagnosis. ${ }^{2}$ Rates in youth are unknown as POTS has only become more recognized in the past 20 years, with the first report of POTS in the pediatric population appearing in 1999. ${ }^{3}$ Due to the nascent knowledge of POTS in youth, it may be inappropriate to apply adult clinical management criteria to youth with POTS. ${ }^{4}$

At least one-third of patients develop POTS symptoms prior to age 18 with a median age of symptom onset at 13.1 years of age. ${ }^{5,6}$ Youth with POTS are typically female $(5: 1)$, Caucasian, and diagnosed between the ages of $12-40$ with over $50 \%$ reporting additional somatic symptoms including chronic fatigue, nausea, and sleep difficulties. ${ }^{5,7-9}$ Up to $50 \%$ of patients have antecedent symptoms of a viral illness with a prolonged course while others have different medical stressors or no identifiable antecedent. ${ }^{10}$

While the individual symptom profile may vary, clinical and physiological symptoms required for diagnosis commonly include both orthostatic difficulties (e.g., dizziness, syncope, blurred vision, weakness, fatigue, "brain fog" or difficulty with concentration) and sympathetic overactivation (e.g., shakiness, palpitations, tremor, anxiety, excessive perspiration, and pain). ${ }^{8}$ Youth with POTS frequently
Correspondence: Ashley N

Department of Pain Medicine, Palliative Care, and Integrative Medicine, Children's Hospitals and Clinics of Minnesota, 2525 Chicago Avenue South, Minneapolis, MN 55304, USA

Tel $+|6| 2-8 \mid 2-9066$

Fax + 1612-813-7199

Email Ashley.junghans@gmail.com 
report the co-occurrence of pain (POTS+pain). It is estimated that $30-88 \%$ of youth with POTS report chronic daily headache, migraine, abdominal pain, and/or musculoskeletal pain. ${ }^{8,11-13}$

Evidence-based methods for treating POTS+pain include pharmacological and physiological interventions with only a few early studies incorporating psychosocial factors. Prospective randomized clinical trials in the pediatric population are limited to only two small studies exploring two pharmacological interventions: midodrine and beta-blockers. ${ }^{14,15}$ Ross and colleagues $(2014)^{14}$ surmised midodrine hydrochloride may be an effective treatment for POTS in some youth aged 12-20 and Chen and colleagues $(2011)^{15}$ reported it can be effective in the treatment of youth aged 6-17 with POTS. Additional studies have shown effectiveness of these pharmacological interventions and have noted additional benefits of exercise when paired with beta-blockers. ${ }^{16,17}$ Other work has demonstrated benefits of exercise, including progressive cardiovascular exercise training in reducing orthostatic intolerance and abnormal cardiac response in adults with POTS, ${ }^{18}$ and improvement in symptoms (including pain) and quality of life in youth. ${ }^{19}$

There is some evidence that youth with POTS experience depression, anxiety, lower quality of life, and catastrophizing, as well as reduced performance in critical areas of functioning including school attendance, sleep, physical activity, and physiological functioning (e.g., fatigue, deconditioning). ${ }^{13,20-22}$ Additionally, "somatic hypervigilance," or a tendency to describe mild sensory experiences in a distressing or intense manner, may be present. ${ }^{20}$ Importantly, pain intensity and depression among youth with POTS has been associated with functional disability independent of magnitude of orthostatic heart rate changes. ${ }^{23}$ While a multidisciplinary treatment approach to assess POTS +pain has been recommended, ${ }^{1,24}$ very few examples of biopsychosocially informed treatment approaches to POTS +pain are available.

Although research on POTS+pain is still emerging and there are confounding variables impacting medical consensus about the POTS diagnosis, patients who struggle with the chronic symptoms associated with POTS+pain (chronic pain, chronic fatigue, orthostatic intolerance, gastrointestinal problems) will continue to seek care, necessitating medical professionals to adopt an informed approach to diagnosis and treatment. The purpose of this review is to: 1) summarize the research on POTS+pain that addresses the existing diagnostic controversies and challenges, 2) provide recommendations for POTS+pain treatment, and 3) discuss what we anticipate to be the future of POTS+pain clinical management and research.

\section{Part I: Challenges And Controversies In The Clinical Management Of Pediatric POTS}

Three major challenges exist when considering pain management in patients with POTS+pain. First, while there are commonly practiced diagnostic approaches to POTS in adults, the diagnostic complexities and heterogeneous presentation of youth with POTS+ pain can impact diagnosis and muddy the waters for medical and family understanding. ${ }^{8}$ Second, there is not a standard treatment approach to POTS +pain in the rehabilitation or pharmacology literature. Third, the psychosocial comorbidities that can exacerbate symptoms of POTS+pain are often not assessed or are left untreated.

\section{Challenge I: Complexities And Misunderstandings}

The diagnosis of POTS is based on some fundamental tenets. Those include the documentation of a sustained heart rate elevation in upright versus supine heart rate, the absence of orthostatic hypotension, the presence of symptoms for a prolonged period of time, and the absence of other potential causes for the symptoms. The diagnostic criteria vary slightly for adults ( $>19$ years old) and adolescents (12-19 years old). ${ }^{1}$

To properly document the elevated heart rate, blood pressure measurements should be taken once the patient has been supine for 5 mins. The patient should then stand upright, and heart rate and blood pressure measurements should be taken at 1-, 3-, 5-, and 10-mins intervals. Adolescents (aged 12-19 years) with a heart rate increase greater than or equal to 40 beats per minute at 10 mins, or absolute upright heart rate of greater than 120 beats per minute, fulfill the initial diagnostic criterion $(>30 \mathrm{bpm}$ for patients $>19$ years old). ${ }^{25}$ Postural tachycardia may also be diagnosed using a head-up tilt table test. ${ }^{8,26,27}$ The postural tachycardia as noted above must also be diagnosed in the absence of orthostatic hypotension (drop in blood pressure of $>20 / 10 \mathrm{~mm} \mathrm{Hg}$ ). These criteria are the same across age groups.

When considering a diagnosis of POTS, symptoms must have been present for greater than six months, although some researchers may set this threshold at three months for 
youth. ${ }^{8,26}$ It is important to note that chronicity is an important defining factor, as some transient causes (e.g. viral infection) may produce similar symptoms to POTS. Finally, symptoms must be present in the absence of other causes. Youth with a POTS diagnosis often begin their diagnostic journey following an acute illness, inactivity due to injury, or an accident (e.g., concussion). These incidents can, in and among themselves, foster a decrease in function and increase in deconditioning. ${ }^{1,18,28-30}$

POTS has been described as both a primary medical condition that can be a standalone diagnosis and, conversely, as a collection of symptoms. ${ }^{1,8,31}$ Garland and colleagues (2015) wrote a well-organized review of POTS and its "overlapping pathophysiological mechanisms": chronic fatigue syndrome, Ehler-Danlos Syndrome and other hypermobile joint syndromes, vasovagal syncope, panic attacks, pain, exercise, caffeine, sympathomimetic medications, anticholinergic medications, anemia, dehydration, and sinus tachycardia. ${ }^{32}$ Just as the signs and symptoms of POTS overlap with several medical disorders (e.g., autonomic dysfunction, cardiomyopathy), so do the typical compensatory physiologic responses associated with medical conditions or decrease in function (e.g., deconditioning, hypovolemia, anxiety). ${ }^{32}$ Diagnosis is further complicated by the fact that patients sometimes present with POTS as well as a concurrent diagnosis of deconditioning. ${ }^{1}$ The presence of deconditioning is considered a differential diagnosis (i.e., weighing the probability of one diagnosis versus the other diagnosis when they present with similar clinical features) for POTS and $70 \%$ of youth present with a concurrent diagnosis of deconditioning, ${ }^{1}$ making it difficult for clinical providers to name POTS as the primary diagnosis. The diagnostic complexity associated with POTS makes it incumbent upon the clinician to perform a thorough history and physical. If another diagnosis is suggested, an appropriate and reasonable workup should be pursued. If necessary, a comprehensive interdisciplinary examination and screening process is warranted.

A further confounding diagnostic challenge is that patients with POTS and their families report ongoing difficulties related to diagnosis, medical stigma, and the challenges related to "living with an invisible illness." 33 They are often told their symptoms are purely psychosomatic in nature or due to anxiety. ${ }^{34,35} \mathrm{It}$ is common for youth with POTS to meet with as many as seven doctors before being diagnosed and to continue to see numerous specialists to determine a treatment plan after diagnosis. ${ }^{6}$ Once a POTS specialist has been identified, the wait to be seen is estimated to be between six to 36 months, further delaying accurate diagnosis and treatment, with youth experiencing an average of 5 years to diagnosis after symptom presentation. ${ }^{33}$

\section{Challenge Il: Lack Of Standardized Approaches To Physical Rehabilitation And Psychopharmacology Physical Rehabilitation Approaches}

The use of guided and progressive exercise and rehabilitation strategies has been shown to reduce signs and symptoms of POTS in adults and adolescents, ${ }^{1,36}$ even to the point of full recovery. ${ }^{37}$ Since more thorough exercise-based research in youth with POTS is lacking, clinical guidelines and protocols based on adult research have been created for youth. ${ }^{1,2,31}$ These include progressively working towards completing one or more hours of moderate to vigorous exercises daily plus strength training $3 \mathrm{x} / \mathrm{week}^{1}{ }^{1}$ Due to intolerance of upright positions, it is often recommended patients start with reclined exercises (e.g., recumbent biking, swimming) and work towards upright activities (e.g., walking, running). ${ }^{1}$ Others have recommended progressive cardiovascular exercise programs targeted at maintaining a $60-70 \%$ maximum suggested heart rate for up to 30 mins. ${ }^{31,38}$

The use of progressive exercise (i.e., aerobic exercise and resistance training) and exposure to orthostatic symptoms has been implemented in both adult and pediatric POTS to improve functional mobility and upright tolerance. 1,19,21,32,39 Exercise and normalization of functional activities are major components in the treatment of POTS, and it is recommended that patients utilize a rehabilitation specialist (e.g., physical or occupational therapist) for implementation and progression. ${ }^{1}$ Self-guided progressive exercising training (with physician implementation) has been reported in adults in programs such as the Dallas Program, which is a progressive exercise program focusing on targeting various heart rate zones and increasing the amount of time a patient can tolerate cardiovascular exercise and upright conditions. ${ }^{39}$ Patients often start the program in a more recumbent or seated position in order to reduce excessive symptom provocation. ${ }^{2}$ In a recent study, $71 \%$ of 103 adults who completed the Dallas Program reported a significant and persistent reduction in POTS symptoms (decrease in heart rate elevation during supine to stand and increased quality of life). ${ }^{39}$ Children's Hospital of Philadelphia has modified the Dallas Program for youth. ${ }^{19}$ There is a discussion on whether patients with POTS should monitor their own heart rates or use perceived exertion as a guide for exercise tolerance. ${ }^{1}$ Patients with POTS often have 
somatic hypervigilance which may limit their ability to progress toward improved functioning. ${ }^{10}$ As such, it is important for the rehabilitation clinician to strike a balance between sign/ symptom monitoring and potentially progress-limiting introspection.

The use of abdominal and lower extremity compression garments to minimize peripheral blood pooling has been used as an adjunct non-pharmacological intervention in adults with orthostatic hypotension ${ }^{40}$ and has been reported as a potential intervention to use in patients with POTS. ${ }^{1,32}$ It is interesting to note that, even though the absence of orthostatic hypotension is used as diagnostic criteria for POTS, ${ }^{1,10,32}$ the use of compression garments has been shown to reduce the intensity of orthostatic symptoms (i.e., imminent syncope, lightheadedness, and nausea) and tachycardia elicited during tilt table testing in teenage POTS patients (13-19 years; 95\% female). ${ }^{41}$ Further research into compression garments' effectiveness as a rehabilitative tool for POTS is warranted.

\section{Pharmacological Treatment Approaches}

Medications are not the mainstay of treatment for pediatric patients with POTS. Appropriate non-pharmacologic interventions can be most important in long-term outcomes and should thus be optimized prior to the consideration of medication therapy. ${ }^{10,31}$ These interventions can include providing education to the patient and family, encouraging increased hydration and salt intake, and recommending appropriate physical therapy and psychological interventions. ${ }^{8,31,43}$ If symptoms persist despite optimization of the non-pharmacologic interventions, the pharmacologic therapies generally focus on supporting blood pressure (i.e., increased intravascular load), decreasing heart rate, and decreasing sympathetic tone. There are no FDA-approved medications for the treatment of POTS in youth, and many patients may demonstrate medication sensitivity. Therefore, the mantra of "start low and go slow" should be adhered to when prescribing medications to these patients. As always, the potential benefits of pharmacotherapy should be weighed against the potential side effects.

Fludrocortisone acetate is a synthetic mineralocorticoid that has shown to be beneficial by increasing the sensitivity of peripheral alpha-adrenergic receptors and promoting vasoconstriction. ${ }^{8}$ Low dose is recommended, as higher doses may result in side effects including significant fluid retention. Beta-blockers as a class have been shown to improve orthostatic symptoms in some patients with POTS by decreasing tachycardia through improved heart rate control. For pediatric patients, propranolol, metoprolol, and labetalol have been used. ${ }^{8}$ Midodrine is an alpha- 1 adrenergic agonist that has been shown to be helpful in the treatment of POTS and its effects are felt within 30-60 mins and last for 2-4 hrs. ${ }^{14}$ However, this medication should not be taken in the evening to minimize the risk of supine hypertension. Midodrine can also be used as dual therapy with fludrocortisone in patients with POTS to improve their symptoms, particularly orthostatic intolerance. ${ }^{8}$ Clonidine is an alpha-2 receptor agonist which inhibits central venous sympathetic outflow and can be helpful in those patients exhibiting signs of sympathetic storms. Pyridostigmine is a cholinesterase inhibitor, and its benefit is conferred by increasing orthostatic blood pressure without exacerbating supine hypertension. ${ }^{8,24,44}$ For a thorough review of pharmacotherapy for POTS, please see the recent article from Miller and Raj. ${ }^{45}$

\section{Challenge III: Psychological Comorbidities}

Literature on psychological comorbidities among patients with POTS has highlighted that poor quality of life, anxiety, concentration deficits, and depression can add to the complexity of POTS and POTS+pain treatment but this research is typically adult-focused. $^{20,46,47}$ In pediatric-focused research, youth report reduced participation in sports, school, and activities even though many used to be high achieving. ${ }^{1,12}$ Many teens with POTS report symptoms of depression, anxiety, and hyperactivity, with one study noting almost one-fourth of youth reported moderate to severe depressive symptoms (13\% and $10 \%$, respectively). ${ }^{5,11,23,47}$ However, other work using the Diagnostic and Statistical Manual (4th ed) has shown similar incidence of depression and anxiety disorders compared to the general population ${ }^{47}$ or has shown no significant association between anxiety/depression and autonomic symptom burden as measured by the Composite Autonomic Symptom Score (COMPASS-31). ${ }^{48}$ At this time, it is not clear if the presentation of mental health symptoms is due to POTS or a primary medical condition.

One point of concern noted in literature is the similarity in presentation between the sympathetic overactivation components of POTS and anxiety, with many individuals being told by at least one physician that the cause of their tachycardia is psychogenic. ${ }^{34}$ There is strong evidence that symptoms of POTS, including tachycardia experienced during venous pooling and hyperpnea during hyperventilation, are not caused by anxiety or solely by "somatic hypervigilance," but are actually compensatory physiological responses to orthostatic stress. ${ }^{30,35,49,50}$ Despite this, medical and mental health practitioners are not always in agreement with respect to treatment approach. For example, 
Kincaid and colleagues (2015) $)^{51}$ present the case of a young adult female who was treated by both psychiatry and emergency medicine after presenting with POTS symptoms, severe headache, and leg pain. She was transferred between the med-psych service and intensive care unit due to disagreement about her presentation. The medical team believed she was presenting with anxiety and that targeting anxiety would improve her symptoms, which guided their medical approach to care. However, while the psychiatry service acknowledged the presence of anxiety, they felt sympathetic nervous system activation was not explained by anxiety alone but was related to her complex POTS presentation. It appears the combination of POTS, pain, and anxiety forces complex medical considerations for the patient and the medical team.

Finally, differences between subjective self-report and objective data (e.g., neuropsychological reports) can create additional complications when trying to distinguish between psychological and physiological symptoms. Preliminary findings describe lack of agreement between self-reports of "brain fog" and processing speed deficiencies with findings of formal measurement of processing speed, attention, working memory, or verbal memory using validated assessment measures. ${ }^{52}$ In one study of youth with POTS enrolled in a chronic pain treatment program, those who felt unable to attend school were over four times more likely to self-report memory difficulties, greater catastrophizing, and POTS symptom intensity. ${ }^{53}$ However, these patients exhibited no differences in scores on objective measures of general intellectual functioning, working memory, verbal and visual memory, and academic skills from patients who did feel they could attend school. Others have theorized that decreased attention and concentration may be the underlying cause of self-reported "memory problems" in youth with POTS. $^{26,54}$

\section{Part II: Recommendations For Treating Pain In Youth With POTS +Pain}

Chronic pain is a common occurrence among individuals with POTS, with headaches, migraines, abdominal pain, muscle cramping, joint pain, leg pain, and musculoskeletal pain being the most commonly reported types of pain. ${ }^{7,8,13,55-57}$ In fact, between $30 \%$ and $88 \%$ of youth with POTS report chronic daily headache, migraine, abdominal pain, and musculoskeletal pain. ${ }^{8,11-13}$ In an examination of 41 young adults with POTS, all but 2 had a history of headache, $73 \%$ had headache onset prior to age 20 , and $12 \%$ reported headache in conjunction with autonomic symptoms. ${ }^{58}$ Among these patients, $61 \%$ were diagnosed with chronic migraine, $29 \%$ episodic migraine, one patient with persistent daily headache, and one with orthostatic headache. Chronic headaches were associated with more severe POTS symptoms, greater perceived symptom disability, lower supine norepinephrine levels, and greater likelihood of blood pressure abnormality during the Valsalva maneuver. ${ }^{58}$ In a study of 57 US adolescents with POTS, $46 \%$ reported migraines, $42 \%$ abdominal pain, and $30 \%$ chronic daily headache. ${ }^{8}$ In another study examining the clinical characteristics of youth with POTS who presented to a general pediatric referral clinic, $88 \%$ reported chronic pain including chronic headache $(69 \%)$ and chronic abdominal pain (39\%). ${ }^{12}$ Interestingly, among 70 adolescents referred to a pediatric headache clinic, 53\% met diagnostic criteria for POTS, and headache type was not predictive of a POTS diagnosis whereas dizziness as a headache trigger and orthostatic headaches were specific to the POTS group. ${ }^{41}$

Literature highlighting psychological adjustment and cognitive functioning among youth with POTS+pain remains scarce but authors describe similar clinical presentations and levels of depression, anxiety, and pain catstrophizing among youth with POTS+pain and pain alone. ${ }^{1,59,60}$ However, the levels of functional disability across these groups are unclear. While Keating and colleagues $(2016)^{60}$ found similar levels of functional disability between youth with POTS+pain and pain alone, Junghans-Rutelonis and colleagues $(2018)^{59}$ found greater functional disability among youth with POTS + pain at the beginning of an intensive rehabilitation program. Parental protective behavior, pain catastrophizing, and attributions of pain to physical causes have been associated with decreased youth functional ability in both groups and parents are now being included in research examining the benefits of parental involvement in treatment programs. ${ }^{60-63}$

As with POTS in general, medications are not the mainstay of treatment for POTS+pain patients. Appropriate nonpharmacologic, biopsychosocially informed interventions should be employed before medications are considered. Medications that have shown to be beneficial for youth with POTS and chronic pain include gabapentin, amitriptyline, and clonidine. ${ }^{64}$ Additionally, multiple groups have recommended an increase in fluid and salt intake. ${ }^{44,65,66}$ However, there is not a consensus on specific quantity increase.

A comprehensive approach to the treatment of POTS + pain is in the very early stages of the study. In a large 
medical center that sees hundreds of adolescents with POTS every year, providers anecdotally found a one-hour group psychoeducation session (i.e., pathophysiology of POTS, natural history of the condition, and explanation of the treatment plan) to be helpful. ${ }^{1}$ Behavioral change components of the psychoeducation group included recommendations to engage in regular cardiovascular exercise, improve eating habits, and regulate sleep routine. ${ }^{1}$ If patients are not able to return to normal functioning based on these recommendations, medications or additional nonpharmacological interventions can be helpful. General nonpharmalogical recommendations for POTS management and treatment that appear to also align with treatment for chronic pain include psychoeducation, cognitive behavioral therapy, adequate water intake, physical activity (including resistance training), returning to regular academic activities, improving sleep hygiene (e.g., behaviors that assist in better quality of sleep), addressing biopsychosocial needs, relaxation strategies via biofeedback technology, and tailoring therapy to a patient's needs or "meeting them where they are at."1,8,31,67,68 Other recommendations for POTS+pain that are not evidence-based include "wearing leotard-type pressure garments" or compression stockings. 1,67

If patients and/or their families struggle with making the recommended behavioral modifications, adherence to prescribed medications, and/or if the patient is struggling with decreased functioning due to POTS+pain or emotional problems (e.g., depression, anxiety), a mental health professional can help address these issues. Cognitive behavioral therapy (CBT) and Acceptance and Commitment Therapy (ACT) have been shown to be effective in primary care settings ${ }^{69}$ and for youth with pain. ${ }^{70-73} \mathrm{CBT}$ and ACT may help youth with POTS+pain as well. Given that youth with POTS often experience catastrophic thoughts that affect their functioning, ${ }^{59}$ therapies that focus on increasing functioning within the context of these types of thoughts can be helpful in decreasing the power that those thoughts have over one's behavior. In one study, increase in acceptance of pain was related to increased overall functioning. ${ }^{73}$

For patients who experience moderate to severe debilitation due to POTS+pain or who are unable to otherwise access adequate treatment, participation in an intensive interdisciplinary pain rehabilitation program (IIPRP) has been shown effective in increasing functioning and improving psychological distress from baseline to follow-up among youth with POTS $^{21}$ and youth with pain. ${ }^{74-79}$ Interdisciplinary evaluation and treatment are considered to be the most efficacious, cost- effective, and evidence-based treatment approaches to chronic pain and have shown preliminary effectiveness for youth with POTS+pain. ${ }^{21,59,80,81}$ Interdisciplinary teams discussed in the literature include health-care providers from the following disciplines: anesthesiology, nursing, occupational therapy, physical therapy, psychology, social work and recreational therapy. ${ }^{82}$ There is currently consensus that IIPRP are 1) beneficial in improving overall functional ability in POTS + pain and 2) can utilize published general rehabilitation clinical guidelines developed to assist with patients who have concurrent diagnoses of POTS+pain. ${ }^{1,8,21,23,24,83}$ Additionally, Johnson and colleagues (2010) proposed an algorithm for POTS treatment that called for a non-pharmacological, interdisciplinary approach for all patients, with use of a pharmacological approach on a case-by-case basis only if necessary. $^{12}$

Recent work has outlined the possibility of including youth with POTS+pain in chronic pain rehabilitation programs and has shown as many as $20 \%$ of patients treated in chronic pain programs have a diagnosis of POTS. ${ }^{75,84}$ For example, Children's Hospital of Philadelphia has reported successful implementation of a modified Dallas Program in the treatment of POTS in youth with concurrent post concussive symptoms (including, but not exclusively, pain). ${ }^{2}$ However, only two interdisciplinary teams treating pediatric POTS+pain have published manuscripts outlining their approaches: The Mayo Clinic and The Cleveland Clinic (see below). The 3-week intensive Pediatric Pain Rehabilitation Center at the Mayo Clinic utilizes an interdisciplinary team approach to care and researchers have published four articles including pre- and post-program data. ${ }^{21,59,75,82}$ The interdisciplinary, CBT-based approach used in that setting has been associated with improvement in depression, pain catastrophizing, anxiety, and functional disability among youth with POTS+pain.

Generalizability to types of pain cannot be gleaned from the Mayo Clinic reports, as only two studies discussed specific pain locations; one study reported improvement in headache and psychosocial functioning, ${ }^{21}$ while the second reported improvement in psychosocial functioning by discharge in a teenage male with chronic headaches. ${ }^{82}$ Additionally, Junghans-Rutelonis and colleagues (2018) ${ }^{59}$ compared youth with chronic pain without POTS to youth with POTS+pain and found youth with POTS+pain reported less back, lower extremity, and chest pain but more "other location" pain (without specifying exact location). In the same study, authors noted greater functional disability at admission when compared to youth with chronic pain without POTS, but similar levels across groups 
at discharge. This study is the only to report improvements in pain intensity at program discharge. In addition, this study is also the only one to examine treatment mediators in youth with POTS+pain, reporting improvement in functional disability that was partially mediated by improvements in depression and pain catastrophizing helplessness (but not in pain intensity or pain catastrophizing magnification or rumination). ${ }^{59}$ Interestingly, Kizilbash and colleagues (2014) discuss improvement in POTS symptoms (e.g., dizziness, visual changes, fainting, rapid heart rate, nausea, vomiting, and weakness) in 15 patients participating in the Mayo Clinic program. ${ }^{1}$ While they note improvement at treatment discharge and 3-month follow-up, they do not present any specific data to clarify findings. It is worthy to note that some authors from this program directly state "resolution of POTS is not the goal of treatment; functional restoration is the primary goal.",21

In the Cleveland Clinic 3-week IIPRP, Kempert (2018) characterizes POTS as a secondary diagnosis to chronic pain diagnoses due to prolonged de-conditioning. ${ }^{84}$ She states physical and occupational therapy may require only slight modifications for POTS compared to other chronic pain diagnoses. While the author acknowledges that POTS is commonly co-morbid with chronic pain, especially chronic headaches, she does not elaborate on the direct treatment of pain in the program but rather focuses on treating POTS within the pain program. ${ }^{84}$ To our knowledge, no data related to POTS+pain symptom change have been included in any pediatric pain rehabilitation program publications to date.

\section{Part III: The Future Of POTS+Pain Clinical Management And Research}

We propose treatment of pediatric POTS+pain moves toward an integrated approach similar to an intensive interdisciplinary rehabilitation program chronic pain model. The current model of IIPRPs includes "meeting the patient where they are at." We propose this also apply to youth with POTS+pain with respect to functioning and symptom tolerance, with a goal of gradual progression towards maximal normalization of function. For treatment of POTS+pain to align with the biopsychosocial understanding of the symptoms and heterogeneous nature of the syndrome, it can be argued it "should" include an interdisciplinary approach that includes utilization of active mind-body techniques and the normalization of life in the realms of sleep, school, social activities, and sports/physical activity. Given the potential for comorbid conditions, the reasonable pharmacological treatment of those conditions should be undertaken in addition to the non-pharmacologic strategies outlined above (e.g. SSRIs for depression or anxiety, anti-inflammatory or biologics for arthritis, immunotherapy for autoimmune conditions). When medications are indicated, we must balance the potential benefits with the potential side effects.

Youth diagnosed with POTS+pain have difficulties not only with orthostatic intolerance and sympathetic nervous system overactivation but also with physical, academic, psychological, and social functioning and coping skills. We believe an IIPRP structure that acknowledges the biopsychosocial model and incorporates the Dallas Protocol for physical functioning, CBT and ACT components for mental health and pain management skills, family psychoeducation, and medication management (when needed), should be the standard treatment recommendation for pediatric POTS + pain among youth who have moderate to severe disability if collaborative outpatient services are not successful. For a list of IIPRPs who treat pediatric chronic pain and who may be a resource for POTS+pain, please see Table 1. To the best of our knowledge, these are the IIPRPs in the United States that treat youth with POTS+pain. However, there may be programs we are not aware of at this time and we are hopeful there will be additional programs in the future. Programs of this nature have shown improvements in parent- and patient-rated functioning and pain. The Mayo Clinic program, in particular, has shown improvement in functioning, psychological adjustment, and pain intensity among youth with POTS+pain. However, no IIPRPs have published data on POTS-specific improvements (e.g., orthostatic intolerance) following participation in the rehabilitative approach. In other words, they report on improvement in pain and functioning but not change or improvement in POTS symptoms.

We agree with recommendations made by Benarroch, Jarjour and Kizilbash and colleagues ${ }^{1,8,10}$ with respect to "practical things" medical and mental health professionals can do to help youth with POTS+pain. These include: 1) Validate the patient including listening to their story in order to develop a positive, therapeutic relationship, 2) set realistic expectations including helping patients understand the differences between chronic pain and acute pain, 3) communicate the biopsychosocial benefits and challenges associated with initiation of an exercise and functioning-based program, and 4) provide clear information to patients, including the presumed benefits of an 
Table I List Of Intensive Interdisciplinary Pain Rehabilitation Programs That Treat POTS+Pain In The United States

\begin{tabular}{|c|c|c|c|c|c|}
\hline Name of program & Hospital & City/State & Type of program & Ages & Disciplines \\
\hline $\begin{array}{l}\text { Stanford Children's Health } \\
\text { Pain Rehabilitation Center }\end{array}$ & $\begin{array}{l}\text { Stanford Children's } \\
\text { Health and the } \\
\text { Lucile Packard } \\
\text { Children's Hospital } \\
\text { Stanford }\end{array}$ & $\begin{array}{l}\text { Palo Alto, } \\
\text { California }\end{array}$ & Outpatient & $\begin{array}{l}\text { Children and } \\
\text { adolescents }\end{array}$ & $\begin{array}{l}\text { CAM, child life, interventionists, } \\
\text { medical, nursing, psychologist, } \\
\text { OT, PT, psychiatry; SW }\end{array}$ \\
\hline $\begin{array}{l}\text { Inpatient Pain } \\
\text { Rehabilitation Program; } \\
\text { Pediatric Amplified Pain } \\
\text { Rehabilitation Program }\end{array}$ & $\begin{array}{l}\text { Benioff Children's } \\
\text { Hospital at } \\
\text { University of } \\
\text { California San } \\
\text { Francisco }\end{array}$ & $\begin{array}{l}\text { San Francisco, } \\
\text { California }\end{array}$ & Intensive inpatient & $\begin{array}{l}\text { 8-18 (younger } \\
\text { and older } \\
\text { considered on } \\
\text { an individual } \\
\text { basis) }\end{array}$ & $\begin{array}{l}\text { AT, biofeedback, CAM, child life, } \\
\text { interventionists, medical, MT, } \\
\text { psychology, rheumatology, } \\
\text { school, SW }\end{array}$ \\
\hline $\begin{array}{l}\text { Adolescent Pain and } \\
\text { POTS Program }\end{array}$ & $\begin{array}{l}\text { Pain Management } \\
\text { Center; Shirley Ryan } \\
\text { Ability Lab }\end{array}$ & $\begin{array}{l}\text { Chicago, } \\
\text { Illinois }\end{array}$ & Intensive outpatient & $\begin{array}{l}\text { Children and } \\
\text { adolescents }\end{array}$ & $\begin{array}{l}\text { Medical, PT, OT, pediatric } \\
\text { psychology }\end{array}$ \\
\hline $\begin{array}{l}\text { Rehabilitation for } \\
\text { Amplified Pain Syndrome }\end{array}$ & $\begin{array}{l}\text { Children's Mercy } \\
\text { Hospital }\end{array}$ & $\begin{array}{l}\text { Kansas City, } \\
\text { Kansas }\end{array}$ & Intensive outpatient & $\begin{array}{l}\text { Children and } \\
\text { adolescents }\end{array}$ & $\begin{array}{l}\text { AT, CAM, Child life, MT, OT, PT, } \\
\text { medical, MT, nursing, psychology, } \\
\text { rheumatology, SW }\end{array}$ \\
\hline $\begin{array}{l}\text { Pain Rehabilitation } \\
\text { Program }\end{array}$ & $\begin{array}{l}\text { Kennedy Krieger } \\
\text { Institute }\end{array}$ & $\begin{array}{l}\text { Baltimore, } \\
\text { Maryland }\end{array}$ & $\begin{array}{l}\text { Both intensive } \\
\text { outpatient and } \\
\text { inpatient }\end{array}$ & $\begin{array}{l}7-18 \text { (younger } \\
\text { and older } \\
\text { considered on } \\
\text { an individual } \\
\text { basis) }\end{array}$ & $\begin{array}{l}\text { Behavioral/pediatric psychology, } \\
\text { Gl, medical, nursing, neurology, } \\
\text { neuropsychology, OT, PT, } \\
\text { psychiatry, school, SW, school }\end{array}$ \\
\hline $\begin{array}{l}\text { Pediatric Pain } \\
\text { Rehabilitation Center }\end{array}$ & $\begin{array}{l}\text { Boston Children's } \\
\text { Hospital }\end{array}$ & $\begin{array}{l}\text { Boston, } \\
\text { Massachusetts }\end{array}$ & Intensive outpatient & $7-18$ & $\begin{array}{l}\text { Medical, nursing, OT, PT, } \\
\text { psychology }\end{array}$ \\
\hline $\begin{array}{l}\text { MiPAIN Intensive } \\
\text { Outpatient Program }\end{array}$ & $\begin{array}{l}\text { C.S. Mott Children's } \\
\text { Hospital }\end{array}$ & $\begin{array}{l}\text { Ann Arbor, } \\
\text { Michigan }\end{array}$ & Intensive outpatient & $11-18$ & $\begin{array}{l}\text { AT, medical, PT, OT, RT, } \\
\text { psychology }\end{array}$ \\
\hline Pediatric Pain Clinic & $\begin{array}{l}\text { Children's Hospitals } \\
\text { and Clinics of } \\
\text { Minnesota }\end{array}$ & $\begin{array}{l}\text { Minneapolis, } \\
\text { Minnesota }\end{array}$ & Outpatient & $\begin{array}{l}\text { Children and } \\
\text { adolescents up } \\
\text { to age } 18\end{array}$ & $\begin{array}{l}\text { Biofeedback, CAM, medical, } \\
\text { nursing, PT, psychology, SW }\end{array}$ \\
\hline $\begin{array}{l}\text { Pediatric Pain } \\
\text { Rehabilitation Center }\end{array}$ & Mayo Clinic & $\begin{array}{l}\text { Rochester, } \\
\text { Minnesota }\end{array}$ & $\begin{array}{l}\text { Hospital-based } \\
\text { intensive outpatient }\end{array}$ & $13-22$ & $\begin{array}{l}\text { Biofeedback, counselors, } \\
\text { medical, nursing, OT, PT, } \\
\text { psychology, psychiatry, RT }\end{array}$ \\
\hline $\begin{array}{l}\text { Inpatient pain } \\
\text { rehabilitation }\end{array}$ & $\begin{array}{l}\text { Children's } \\
\text { Specialized Hospital }\end{array}$ & $\begin{array}{l}\text { Mountainside, } \\
\text { New Jersey }\end{array}$ & Inpatient & ||$-2 \mid$ & $\begin{array}{l}\text { Child life, OT, PT, RT, pain } \\
\text { psychology, school }\end{array}$ \\
\hline $\begin{array}{l}\text { Functional Independence } \\
\text { Restoration Program }\end{array}$ & $\begin{array}{l}\text { Cincinnati Children's } \\
\text { Hospital }\end{array}$ & $\begin{array}{l}\text { Cincinnati, } \\
\text { Ohio }\end{array}$ & Inpatient & $10-18$ & Medical, OT, PT, psychology \\
\hline $\begin{array}{l}\text { Pediatric Pain } \\
\text { Rehabilitation Program }\end{array}$ & $\begin{array}{l}\text { Cleveland Clinic } \\
\text { Children's }\end{array}$ & $\begin{array}{l}\text { Cleveland, } \\
\text { Ohio }\end{array}$ & $\begin{array}{l}\text { Outpatient - clinic, } \\
\text { group treatment, } \\
\text { individual/family; } \\
\text { inpatient/day } \\
\text { hospital }\end{array}$ & $8-18$ & $\begin{array}{l}\text { Medical, nursing, nutrition, OT, } \\
\text { PT, psychiatry, psychology, SW }\end{array}$ \\
\hline $\begin{array}{l}\text { Center for Amplified } \\
\text { Musculoskeletal Pain }\end{array}$ & $\begin{array}{l}\text { Children's Hospital } \\
\text { of Philadelphia }\end{array}$ & $\begin{array}{l}\text { Philadelphia, } \\
\text { Pennsylvania }\end{array}$ & $\begin{array}{l}\text { Outpatient AMPS, } \\
\text { therapeutic hospital } \\
\text { treatment }\end{array}$ & $\begin{array}{l}\text { Children and } \\
\text { adolescents }\end{array}$ & $\begin{array}{l}\text { AT, medical, OT, PT, psychology, } \\
\text { rheumatology, SW }\end{array}$ \\
\hline
\end{tabular}

(Continued) 
Table I (Continued).

\begin{tabular}{|l|l|l|l|l|l|}
\hline Name of program & Hospital & City/State & Type of program & Ages & Disciplines \\
\hline $\begin{array}{l}\text { Pediatric Pain } \\
\text { Rehabilitation Program }\end{array}$ & $\begin{array}{l}\text { Seattle Children's } \\
\text { Hospital }\end{array}$ & $\begin{array}{l}\text { Seattle, } \\
\text { Washington }\end{array}$ & Intensive outpatient & $\begin{array}{l}\text { 7-18 (younger } \\
\text { and older } \\
\text { considered on } \\
\text { an individual } \\
\text { basis) }\end{array}$ & $\begin{array}{l}\text { Medical, nursing, OT, PT, pain } \\
\text { psychology, school, SW }\end{array}$ \\
\hline
\end{tabular}

Notes: All of the intensive interdisciplinary treatment programs in this table treat patients who have with Pain+POTS. The Mayo Clinic, Shirley Ryan Ability Lab, and a multidisciplinary POTS clinic based in the Cardiology Department at Children's Mercy Hospital also treat patients with POTS without pain.

Abbreviations: AT, art therapy, MT, music therapy, PT, physical therapy, OT, occupational therapy, RT, recreational therapy, SW, social work, GI, gastroenterology, CAM, complementary and alternative medicine and can include massage, acupuncture, and integrative medicine. The above table information was gathered through electronically available information as well as direct email correspondence with program staff.

interdisciplinary approach to POTS+pain treatment as outlined in this paper. In order to help medical, rehabilitation, and mental health staff to feel prepared for implementing this approach, we recommend utilization of motivational interviewing techniques so that staff can best meet youth and families "where they are at" with regard to treatment planning. ${ }^{85-87}$ We also agree with Raj and Robertson's five big needs for the future of POTS, especially pertaining to their third assertion that improved physician awareness about POTS is needed to improve accurate diagnosis and access to care. ${ }^{88}$

In the future, clinical practice and research efforts must expand to include necessary topics to further evidencebased care for youth with POTS and POTS+pain. From a rehabilitation perspective, differentiating treatment for those patients with POTS who present with de-conditioning versus those who are not classically de-conditioned is of benefit. While medications are not the mainstay of treatment, there are some that can be helpful for youth with POTS+pain and we strongly encourage further research in this area to aid in pediatric prescription guidelines. We have highlighted the importance of a biopsychosocial approach that includes psychological treatment and feel it is vital to incorporate trained mental health professionals in the assessment and treatment of co-morbid anxiety, depression, and other adjustment difficulties. In sum, contributions to the literature by health-care providers representing diverse pediatric specialties will help advance the discussion around POTS and POTS+pain diagnostic complexities and misunderstandings and help move the field toward the shared goal of diagnostic and treatment consensus.

\section{Disclosure}

The authors declare that they have no conflict of interest.

\section{References}

1. Kizilbash SJ, Ahrens SP, Bruce BK, et al. Adolescent fatigue, POTS, and recovery: a guide for clinicians. Curr Probl Pediatr Adolesc Health Care. 2014;44(5):108-133. doi:10.1016/j.cppeds.2013.12.014

2. Miranda NA, Boris JR, Kouvel KM, Stiles L. Activity and exercise intolerance after concussion: identification and management of postural orthostatic tachycardia syndrome. J Neurol Phys Ther. 2018;42(3):163.

3. Stewart JM, Gewitz MH, Weldon A, Munoz J. Patterns of orthostatic intolerance: the orthostatic tachycardia syndrome and adolescent chronic fatigue. J Pediatr. 1999;135(2):218-225. doi:10.1016/ s0022-3476(99)70025-9

4. Singer W, Sletten DM, Opfer-Gehrking TL, Brands CK, Fischer PR, Low PA. Postural tachycardia in children and adolescents: what is abnormal? J Pediatr. 2012;160(2):222-226. doi:10.1016/j.jpeds.2011. 08.054

5. Boris JR, Bernadzikowski T. Demographics of a large paediatric postural orthostatic tachycardia syndrome program. Cardiol Young. 2018;28(5):668-674. doi:10.1017/S1047951117002888

6. Raj SR, Stiles L, Shaw B, et al. The diagnostic experience in postural tachycardia syndrome: insights from a cross-sectional communitybased survey. In 27th International Symposium on the autonomic nervous system. Clin Auton Res. 2016;26:356. doi:10.1007/s10286016-0362-x

7. Deb A, Morgenshtern K, Culbertson CJ, Wang LB, Hohler AD. A survey-based analysis of symptoms in patients with postural orthostatic tachycardia syndrome. Baylor Univ Med Cent Proc. 2015;28 (2):157-159. Taylor \& Francis. doi:10.1080/08998280.2015.11929 217

8. Jarjour IT. Postural tachycardia syndrome in children and adolescents. Semin Pediatr Neurol. 2013;20(1):18-26. WB Saunders. doi:10.1016/j.spen.2013.01.001

9. Strassheim V, Welford J, Ballantine R, Newton JL. Managing fatigue in postural tachycardia syndrome (PoTS): the Newcastle approach. Auton Neurosci. 2018;215:56-61. doi:10.1016/j.autneu.2018.02.003

10. Benarroch EE. Postural tachycardia syndrome: a heterogeneous and multifactorial disorder. Mayo Clin Proc. 2012;87(12):1214-1225. Elsevier. doi:10.1016/j.mayocp.2012.08.013

11. Hernandez A, Jarjour L, Jarjour I. Pediatric Postural Tachycardia Syndrome (POTS): a children's hospital experience. Neurology. 2012;78 (1):P05. 205. doi:10.1212/WNL.78.1_MeetingAbstracts.P05.205

12. Johnson JN, Mack KJ, Kuntz NL, Brands CK, Porter CJ, Fischer PR. Postural orthostatic tachycardia syndrome: a clinical review. Pediatr Neurol. 2010;42(2):77-85. doi:10.1016/j.pediatrneurol.2009.07.002

13. Ojha A, Chelimsky TC, Chelimsky G. Comorbidities in pediatric patients with postural orthostatic tachycardia syndrome. J Pediatr. 2011;158(1):20-23. doi:10.1016/j.jpeds.2010.07.005 
14. Ross AJ, Ocon AJ, Medow MS, Stewart JM. A double-blind placebocontrolled cross-over study of the vascular effects of midodrine in neuropathic compared with hyperadrenergic postural tachycardia syndrome. Clin Sci. 2014;126(4):289-296. doi:10.1042/CS20130222

15. Chen L, Wang L, Sun J, et al. Midodrine hydrochloride is effective in the treatment of children with postural orthostatic tachycardia syndrome. Circ J. 2011;75(4):927-931. doi:10.1253/circj.cj-10-0514

16. Lai CC, Fischer PR, Brands CK, et al. Outcomes in adolescents with postural orthostatic tachycardia syndrome treated with midodrine and $\beta$-blockers. Pacing Clin Electrophysiol. 2009;32(2):234-238. doi:10.1111/j.1540-8159.2008.02207.x

17. Fu Q, VanGundy TB, Shibata S, Auchus RJ, Williams GH, Levine BD. Exercise training versus propranolol in the treatment of the postural orthostatic tachycardia syndrome. Hypertension. 2011;58 (2):167-175. doi:10.1161/HYPERTENSIONAHA.111.172262

18. Fu Q, VanGundy TB, Galbreath MM, et al. Cardiac origins of the postural orthostatic tachycardia syndrome. $\mathrm{J}$ Am Coll Cardiol. 2010;55(25):2858-2868. doi:10.1016/j.jacc.2010.02.043

19. Fu Q, Levine BD. Exercise and non-pharmacological treatment of POTS. Auton Neurosci. 2018;1(215):20-27. doi:10.1016/j.autneu.2018.07.001

20. Benrud-Larson LM, Sandroni P, Haythornthwaite JA, Rummans TA, Low PA. Correlates of functional disability in patients with postural tachycardia syndrome: preliminary cross-sectional findings. Health Psychol. 2003;22(6):643. doi:10.1037/0278-6133.22.6.643

21. Bruce BK, Harrison TE, Bee SM, et al. Improvement in functioning and psychological distress in adolescents with postural orthostatic tachycardia syndrome following interdisciplinary treatment. Clin Pediatr (Phila). 2016;55(14):1300-1304. doi:10.1177/0009922816638663

22. McTate EA, Weiss KE. Psychosocial dimensions and functioning in youth with postural orthostatic tachycardia syndrome. Clin Pediatr (Phila). 2016;55(10):979-982. doi:10.1177/0009922815616890

23. Kritzberger CJ, Antiel RM, Wallace DP, et al. Functional disability in adolescents with orthostatic intolerance and chronic pain. $J$ Child Neurol. 2011;26(5):593-598. doi:10.1177/0883073810390366

24. Boris JR. Postural orthostatic tachycardia syndrome in children and adolescents. Auton Neurosci. 2018;1(215):97-101. doi:10.1016/j. autneu.2018.05.004

25. Grubb BP, Kanjwal Y, Kosinski DJ. The postural tachycardia syndrome: a concise guide to diagnosis and management. J Cardiovasc Electrophysiol. 2006;17(1):108-112. doi:10.1111/j.1540-8167.2005.00318.x

26. Arnold AC, Haman K, Garland EM, et al. Cognitive dysfunction in postural tachycardia syndrome. Clin Sci. 2015;128(1):39-45. doi:10. 1042/CS20140251

27. Cheshire WP, Goldstein DS. Autonomic uprising: the tilt table test in autonomic medicine. Clin Auton Res. 2019;29:215-230. doi:10.1007/ s10286-019-00598-9

28. Burkhardt BE, Fischer PR, Brands CK, et al. Exercise performance in adolescents with autonomic dysfunction. J Pediatr. 2011;158(1):1519. doi:10.1016/j.jpeds.2010.07.020

29. Parsaik A, Allison TG, Singer W, et al. Deconditioning in patients with orthostatic intolerance. Neurology. 2012;79(14):1435-1439. doi:10.1212/WNL.0b013e31826d5f95

30. Joyner MJ, Masuki S. POTS versus deconditioning: the same or different? Clin Auton Res. 2008;18(6):300. doi:10.1007/s10286-0080487-7

31. Stewart JM, Boris JR, Chelimsky G, et al. Pediatric disorders of orthostatic intolerance. Pediatrics. 2018;141(1):e20171673. doi:10.1542/ peds.2017-1673

32. Garland EM, Celedonio JE, Raj SR. Postural tachycardia syndrome: beyond orthostatic intolerance. Curr Neurol Neurosci Rep. 2015;15 (9):60. doi:10.1007/s11910-015-0583-8

33. Stiles LE, Cinnamon J, Balan I. The patient perspective: what postural orthostatic tachycardia syndrome patients want physicians to know. Auton Neurosci. 2018;215:121-125. doi:10.1016/j.autneu.2018.06.002
34. Ali YS, Daamen N, Jacob G, et al. Orthostatic intolerance: a disorder of young women. Obstet Gynecol Surv. 2000;55(4):251-259. doi:10.1097/00006254-200004000-00025

35. Masuki S, Eisenach JH, Johnson CP, et al. Excessive heart rate response to orthostatic stress in postural tachycardia syndrome is not caused by anxiety. J Appl Physiol. 2007;102(3):896-903. doi:10.1152/ japplphysiol.00927.2006

36. Stewart JM. A new guideline for diagnosis and treatment of syncope in children and adolescents that stimulates further thought and discussion. Sci Bull. 2018;63(23):1527. doi:10.1016/j.scib.2018.09.020

37. Shibata S, Fu Q, Bivens TB, Hastings JL, Wang W, Levine BD. Short-term exercise training improves the cardiovascular response to exercise in the postural orthostatic tachycardia syndrome. J Physiol. 2012;590(15):3495-3505. doi:10.1113/jphysiol.2012.233858

38. Mohr LD. A case report and review of postural orthostatic syndrome in an adolescent. J Pediatr Health Care. 2017;31(6):717-723. doi:10.1016/j.pedhc.2017.04.013

39. George SA, Bivens TB, Howden EJ, et al. The international POTS registry: evaluating the efficacy of an exercise training intervention in a community setting. Heart Rhythm. 2016;13(4):943-950. doi:10.1016/ j.hrthm.2015.12.012

40. Smit AA, Wieling W, Fujimura J, et al. Use of lower abdominal compression to combat orthostatic hypotension in patients with autonomic dysfunction. Clin Auton Res. 2004;14(3):167-175. doi:10.1007/s10286004-0187-x

41. Heyer GL, Fedak EM, LeGros AL. Symptoms predictive of postural tachycardia syndrome (POTS) in the adolescent headache patient. $J$ Headache Pain. 2013;53(6):947-953. doi:10.1111/head.2013.53. issue-6

42. Wells R, Elliott AD, Mahajan R, et al. Efficacy of therapies for postural tachycardia syndrome: systematic review and meta-analysis. Mayo Clin Proc. 2018;93:1043-1103. doi:10.1016/j.mayocp.2018.01.025

43. Sheldon RS, Grubb BP, Olshansky B, et al. 2015 Heart Rhythm Society expert consensus statement on the diagnosis and treatment of postural tachycardia syndrome, inappropriate sinus tachycardia, and vasovagal syncope. Heart Rhythm. 2015;12(6):e41-e63. doi:10. 1016/j.hrthm.2015.03.029

44. Conner R, Sheikh M, Grubb B. Postural orthostatic tachycardia syndrome (POTS): evaluation and management. $\mathrm{Br} J$ Med Pract. 2012;5(4):540.

45. Miller AJ, Raj SR. Pharmacotherapy for postural tachycardia syndrome. Auton Neurosci. 2018;1(215):28-36. doi:10.1016/j.autneu. 2018.04.008

46. Anderson JW, Lambert EA, Sari CI, et al. Cognitive function, healthrelated quality of life, and symptoms of depression and anxiety sensitivity are impaired in patients with the postural orthostatic tachycardia syndrome (POTS). Front Physiol. 2014;25(5):230.

47. Raj V, Haman KL, Raj SR, et al. Psychiatric profile and attention deficits in postural tachycardia syndrome. J Neurol Neurosurg Psychiatry. 2009;80(3):339-344. doi:10.1136/jnnp.2008.144360

48. Rea NA, Campbell CL, Cortez MM. Quantitative assessment of autonomic symptom burden in postural tachycardia syndrome (POTS). J Neurol Sci. 2017;377:35-41. doi:10.1016/j.jns.2017.03. 032

49. Mathias CJ, Low DA, Iodice V, Owens AP, Kirbis M, Grahame R. Postural tachycardia syndrome - current experience and concepts. Nat Rev Neurol. 2012;8(1):22. doi:10.1038/nrneurol.2011.187

50. Stewart JM, Medow MS, Cherniack NS, Natelson BH. Postural hypocapnic hyperventilation is associated with enhanced peripheral vasoconstriction in postural tachycardia syndrome with normal supine blood flow. Am J Physiol Heart Circ Physiol. 2006;291(2): H904-H913. doi:10.1152/ajpheart.01359.2005

51. Kincaid BB, Muzyk AJ, Kanter RJ, Preud'Homme XA. Manifestations of anxiety? Explaining tachycardia and hypertension in a patient with POTS. Fam Med Med Sci Res. 2015;4(153):2. 
52. Jarjour IT, Evankovich K, Hernandez A, Jarjour L. Neuropsychological profiles in adolescents with Postural Tachycardia Syndrome (POTS). Neurology. 2013;80(7):P03-P040.

53. Owens M, Sawchuk N, Harbeck-Weber C. Disruption of school attendance among adolescents/young adults with POTS and chronic pain. J Pain. 2018;19(3):S108. doi:10.1016/j.jpain.2017.12.257

54. Arnold AC, Ng J, Raj SR. Postural tachycardia syndrome - diagnosis, physiology, and prognosis. Auton Neurosci. 2018;1(215):3-11. doi:10.1016/j.autneu.2018.02.005

55. Bagai K, Song Y, Ling JF, et al. Sleep disturbances and diminished quality of life in postural tachycardia syndrome. $J$ Clin Sleep Med. 2011;7(02):204-210.

56. Freeman R, Wieling W, Axelrod FB, et al. Consensus statement on the definition of orthostatic hypotension, neurally mediated syncope and the postural tachycardia syndrome. Clin Auton Res. 2011;21 (2):69-72. doi:10.1007/s10286-011-0119-5

57. Mack KJ, Johnson JN, Rowe PC. Orthostatic intolerance and the headache patient. Semin Pediatr Neurol. 2010;17(2):109-116. WB Saunders. doi:10.1016/j.spen.2010.04.006

58. VanderPluym J, Hoffman-Snyder C, Khoury J, Goodman B. Migraine in Postural Orthostatic Tachycardia Syndrome (POTS). Neurology. 2018;90(15):P3126. doi:10.1212/WNL.0000000000005560

59. Junghans-Rutelonis AN, Craner JR, Ale CM, Harbeck-Weber C, Fischer PR, Weiss KE. Youth with chronic pain and postural orthostatic tachycardia syndrome (POTS): treatment mediators of improvement in functional disability. J Clin Psychol Med Settings. 2018;25(4):471-484. doi:10.1007/s10880-018-9558-7

60. Keating EM, Antiel RM, Weiss KE, et al. Parental perceptions of pediatric pain and POTS-related disability. Clin Pediatr (Phila). 2017;56(13):1185-1192. doi:10.1177/0009922816681137

61. Carter BD, Threlkeld BM. Psychosocial perspectives in the treatment of pediatric chronic pain. Pediatr Rheumatol. 2012;10(1):15. doi:10.1186/1546-0096-10-24

62. Kluck BN, Junghans-Rutelonis AN, Jones AE, Fischer PR, Weiss KE. Adolescent chronic fatigue and orthostatic intolerance: relationships between parental attributes and child functioning. Clin Pediatr (Phila). 2017;56(1):85-89. doi:10.1177/0009922816644730

63. Weiss KE, Junghans-Rutelonis AN, Aaron R, et al. Improving distress and behaviors for parents of adolescents with chronic pain enrolled in an intensive interdisciplinary pain program. Clin J Pain. 2019;35(9):;772-779. doi:10.1097/AJP.0000000000000737

64. Grégoire MC, Finley GA. Drugs for chronic pain in children: a commentary on clinical practice and the absence of evidence. Pain Res Manage. 2013;18(1):47-50. doi:10.1155/2013/402863

65. Abed H, Ball PA, Wang LX. Diagnosis and management of postural orthostatic tachycardia syndrome: a brief review. J Geriatr Cardiol. 2012;9(1):61. doi:10.3724/SP.J.1263.2012.00061

66. Low PA, Sandroni P, Joyner M, WK SHEN. Postural tachycardia syndrome (POTS). J Cardiovasc Electrophysiol. 2009;20(3):352358. doi:10.1111/j.1540-8167.2008.01407.x

67. Mokri B, Low PA. Orthostatic headaches without CSF leak in postural tachycardia syndrome. Neurology. 2003;61(7):980-982. doi:10. 1212/01.wnl.0000085868.37963.7d

68. Nestoriuc Y, Martin A, Rief W, Andrasik F. Biofeedback treatment for headache disorders: a comprehensive efficacy review. Appl Psychophysiol Biofeedback. 2008;33(3):125-140. doi:10.1007/s10484-008-9060-3

69. Funderburk JS, Shepardson RL, Wray J, et al. Behavioral medicine interventions for adult primary care settings: a review. Families, Systems, \& Health. 2018;36(3):368. doi:10.1037/fsh0000333

70. Ehde DM, Dillworth TM, Turner JA. Cognitive-behavioral therapy for individuals with chronic pain: efficacy, innovations, and directions for research. Am Psychologist. 2014;69(2):153. doi:10.1037/a0035747

71. Wetherell JL, Afari N, Rutledge T, et al. A randomized, controlled trial of acceptance and commitment therapy and cognitive-behavioral therapy for chronic pain. Pain. 2011;152(9):2098-2107. doi:10.1016/ j.pain.2011.05.016
72. Wicksell RK, Olsson GL, Hayes SC. Mediators of change in acceptance and commitment therapy for pediatric chronic pain. Pain. 2011;152(12):2792-2801. doi:10.1016/j.pain.2011.09.003

73. Weiss KE, Hahn A, Wallace DP, Biggs B, Bruce BK, Harrison TE Acceptance of pain: associations with depression, catastrophizing, and functional disability among children and adolescents in an interdisciplinary chronic pain rehabilitation program. J Pediatr Psychol. 2013;38(7):756-765. doi:10.1093/jpepsy/jst028

74. Benore E, D’Auria A, Banez GA, Worley S, Tang A. The influence of anxiety reduction on clinical response to pediatric chronic pain rehabilitation. Clin J Pain. 2015;31(5):375-383. doi:10.1097/AJP.000000 0000000127

75. Bruce BK, Ale CM, Harrison TE, et al. Getting back to living further evidence for the efficacy of an interdisciplinary pediatric pain treatment program. Clin J Pain. 2017;33(6):535-542. doi:10.1097/ AJP.0000000000000433

76. Hechler T, Kanstrup M, Holley AL, et al. Systematic review on intensive interdisciplinary pain treatment of children with chronic pain. Pediatrics. 2015;136(1):115-127. doi:10.1542/peds.2014-3319

77. Hirschfeld G, Hechler T, Dobe M, et al. Maintaining lasting improvements: one-year follow-up of children with severe chronic pain undergoing multimodal inpatient treatment. $J$ Pediatr Psychol. 2012;38(2):224-236. doi:10.1093/jpepsy/jss115

78. Odell S, Logan DE. Pediatric pain management: the multidisciplinary approach. J Pain Res. 2013;6:785. doi:10.2147/JPR

79. Simons LE, Sieberg CB, Conroy C, et al. Children with chronic pain: response trajectories after intensive pain rehabilitation treatment. $J$ Pain. 2018;19(2):207-218. doi:10.1016/j.jpain.2017.10.005

80. Gatchel RJ, Okifuji A. Evidence-based scientific data documenting the treatment and cost-effectiveness of comprehensive pain programs for chronic nonmalignant pain. J Pain. 2006;7(11):779-793. doi:10.1016/j.jpain.2006.08.005

81. Gatchel RJ, McGeary DD, McGeary CA, Lippe B. Interdisciplinary chronic pain management: past, present, and future. Am Psychologist. 2014;69(2):119. doi:10.1037/a0035514

82. Bruce BK, Weiss KE, Harrison TE, et al. Interdisciplinary treatment of maladaptive behaviors associated with postural orthostatic tachycardia syndrome (POTS): a case report. J Clin Psychol Med Settings. 2016;23(2):147-159. doi:10.1007/s10880-015-9438-3

83. Landry BW, Fischer PR, Driscoll SW, et al. Managing chronic pain in children and adolescents: a clinical review. Pain Manag Res. 2015;7 (11):S295-S315.

84. Kempert H Can intensive physical and occupational therapy be tolerated by adolescents with postural ortostatic tachycardia syndrome (POTS) [internet]? Elite learning rehab insider. 2018. Available from: https:// www.elitecme.com/resource-center/rehabilitation-therapy/can-intensivephysical-and-occupational-therapy-be-tolerated-by-adolescents-with-pos tural-orthostatic-tachycardia-syndrome-pots/. Accessed November 19, 2018.

85. Linden A, Butterworth SW, Prochaska JO. Motivational interviewing-based health coaching as a chronic care intervention. J Eval Clin Pract. 2010;16(1):166-174. doi:10.1111/j.1365-2753.2009.01 300.x

86. Rollnick S, Miller WR, Butler C. Motivational Interviewing in Health Care: Helping Patients Change Behavior. Guilford Press; 2008.

87. Thomas ML, Fahey KF, Christine Miaskowski RN. A randomized, clinical trial of education or motivational-interviewing-based coaching compared to usual care to improve cancer pain management. Oncol Nurs Forum. 2012;39(1):39. Oncology Nursing Society. doi:10.1188/12.ONF.39-49

88. Raj SR, Robertson D. Moving from the present to the future of postural tachycardia syndrome - what we need. Auton Neurosci. 2018;215:126-128. doi:10.1016/j.autneu.2018.06.007 


\section{Publish your work in this journal}

The Journal of Pain Research is an international, peer reviewed, open access, online journal that welcomes laboratory and clinical findings in the fields of pain research and the prevention and management of pain. Original research, reviews, symposium reports, hypothesis formation and commentaries are all considered for publication. The manuscript management system is completely online and includes a very quick and fair peer-review system, which is all easy to use. Visit http:// www.dovepress.com/testimonials.php to read real quotes from published authors. 